\title{
Obstacles to applying knowledge management in small enterprises in the Egyptianconstruction sector, Review
}

\author{
Amany Magdy ${ }^{\mathrm{a}}$, Prof. Dr. Ali Eid ${ }^{\mathrm{b}}$, Prof. Dr. Laila Khodeir ${ }^{\mathrm{c}}$ \\ ${ }^{a}$ Candidate of Masters, Faculty of Engineering, Department of architecture, \\ Ain Shams University, Cairo, Egypt \\ ${ }^{b}$ Professor of Architecture and Project Management, Faculty of Engineering, \\ Department ofArchitecture, Ain Shams University, Cairo, Egypt \\ ${ }^{c}$ Professor of Project Management, Faculty of Engineering, Department of \\ Architecture, AinShams University, Cairo, Egypt.
}

\begin{abstract}
The adoption of knowledge management has become an essential pillar of modern management in the entire world. Knowledge has been recognized as one of the most important assets of any organization, especially in a knowledge-intensive industry such as construction. The application of knowledge management contributes to supporting the transfer of knowledge between stakeholders and preventing "re-inventing the wheel". Knowledge management is a tool for improving organizational performance and achieving a competitive advantage. A review of the literature shows that there are many more challenges for small construction enterprises in adopting knowledge management systems compared to large enterprises. Because small companies play a prominent role in the contracting sector, they must strive to keep pace with the huge revolution in modern management and the successful application of knowledge management by removing obstacles to its application. This paper presents an overview to identify the obstacles that hinder the application of knowledge management in small construction enterprises. By reviewing the relevant literature, the results showed that the main obstacles associated with the adoption of knowledge management are lack of awareness of the concept of knowledge management, lack of funding, time constraints, nature of construction projects, staff resistance, and lack of documentation.
\end{abstract}

\section{KEYWORDS}

knowledge management (KM), obstacles, small construction enterprises (SCEs), construction. 


\section{INTRODUCTION:}

Our era today is characterized by rapid development and change. It is witnessing an amazing revolution in information technology. It creates new opportunities for the construction industry by providing information from all its sources. The construction sector is a knowledge-intensive industry where numerous knowledge accumulates (Rowley, 2007). Knowledge management $(\mathrm{KM})$ is distinguished by its ability to create, share, and organize knowledge for individuals and groups, and this knowledge becomes available throughout participation. KM application is the best way to invest intellectual capital by making use of the experiences inherent in the minds of individuals, contributing to improving the performance of employees, and raising the efficiency of institutions.

Recently, with the emergence of a new framework based on the use of Building Information Modeling (BIM) technology, which is one of the prominent tools of the 21st century in the construction industry. This framework manages information throughout the building's life cycle (Aouad \& Arayici, 2010). Although BIM is an integrated information framework, it focuses on information with little attention and utilization of knowledge (Boyes, 2016). BIM is not developed enough to create and gain knowledge; KM is a stand-alone process isolated from BIM application (Liu et al., 2013). Many researchers have realized the necessity to incorporate knowledge into BIM to permit incessant development in BIM supported projects (Boyes, 2016).

Although knowledge is classified as an important asset and a competitive resource in the construction sector (Rowley, 2007), the fragmentation of construction knowledge is identified as one of the major challenges facing the construction industry. This fragmentation makes it difficult to transfer knowledge among project participants and contributes to the waste of knowledge within the sector(Liu et al., 2013).

On the other hand, small and medium enterprises (SMEs) have become a priority in economic and institutional reform programs for various countries. This interest comes in light of the increase in the number of these companies, and the increase in their contribution to the Gross Domestic Product (GDP). SMEs make up approximately 90 percent of the total number of companies all over the world (Muriithi, 2017). Studies in this regard show that there is as yet a shortage of realization concerning the requirements of small enterprises (SEs) in managing knowledge (Durst et al., 2013). In this context, this paper tries to identify the principal barriers to the application of $\mathrm{KM}$ in small construction enterprises. 


\section{LITERATURE REVIEW:}

\subsection{Definition of Knowledge:}

Knowledge is a complicated concept which comprises information and skills gained through experience. Knowledge exists in persons, groups, and organizations, in many forms. The acquisition of an employee's knowledge is important for the organization. Essential decisions are set up on experience and information that is ordinarily shared informally (Hari et al., 2004.(

There are different outlines for distinctive between various types of knowledge. One proposed outline for categorizing the knowledge discriminates between explicit knowledge and tacit knowledge(Nonaka \& Takeuchi, 1995). Tacit knowledge is the knowledge that is embedded in the mind through personal experience and skills. It is hard to formalize, encode, communicate, and present in tangible form. Many authors estimate that $80 \%$ of important knowledge is tacit knowledge(O'Dell \& Leavitt, 2004; Rumizen, 2002). In contrast, Explicit knowledge is the knowledge that is easily recorded, encoded, and articulated. It is usually embedded in various formats like books, databases, datasheets, and reports, etc. Moreover; it can be captured, shared, communicated, and stored.

The interaction between explicit and tacit knowledge is described in the SECI model. It identifies four processes that are ordinarily used by organizations for knowledge transformation from one type of knowledge to another. This model includes socialization, externalization, combination, and internalizations(Nonaka \& Takeuchi, 1995.(

Socialization: This process includes the sharing of tacit knowledge between people. It allows exchanging experiences through collective activities such as seminars, discussions, presentations, conferences, and workshops. Social processes play a significant role in transforming individual knowledge into collective knowledge(Walsh, 1995). Externalization: It is the process in which tacit knowledge is translated into a form that is easy for people to comprehend(Nonaka \& Takeuchi, 1995). Tacit knowledge is stored in a type of documentation. It includes techniques such as concepts, words, or figurative language. Combination: The process in which knowledge is gathered throughout the organization and aggregated into a more effective form than explicit knowledge(Huang \& Yeh, 2011). Internalization: It is converting explicit knowledge provided by the organization or external sources into tacit knowledge applied personally (Nonaka \& Takeuchi, 1995). 


\subsection{Introduction of knowledge management:}

Despite the wide literature on knowledge management (KM), it is hard to define (Earl, 2001). KM cannot be restricted to a single definition and is presented as being varied in various fields. There are several definitions for KM clarifying the distinctions in the content and scope. According to Macintosh (1997), KM is "The identification and analysis of available and required knowledge, and the subsequent planning and control of actions to develop knowledge assets to fulfill individual and/or organizational objectives" (Macintosh, 1997). Besides, van Donk (2005) defined $\mathrm{KM}$ as "Knowledge Management is the process of acquiring, developing, measuring, distributing, and providing a return on organizational intellectual assets through a set of defined methods, tools, techniques and values" (van Donk \& Riezebos, 2005). the researchers concluded the

definition of $\mathrm{KM}$ as a set of processes or activities for evolving and using knowledge to gain or enhance the assortment of results like organizational performance, or competitive advantage, etc (Bakar et al., 2012).

Recently, there is plenty of studies on KM because many researchers have paid great attention to $\mathrm{KM}$ in various fields. According to Scopus database ${ }^{1}$ statistics during the past two decades from 2000 to 2020, the ranking of published KM documents by subject area is as follows; the field of computer science ranked first with $30.6 \%$, then business, management, and accounting by $16 \%$, while the engineering field ranked third with $12.4 \%$, respectively (Scopus, 2021c) as shown in Figure 1.

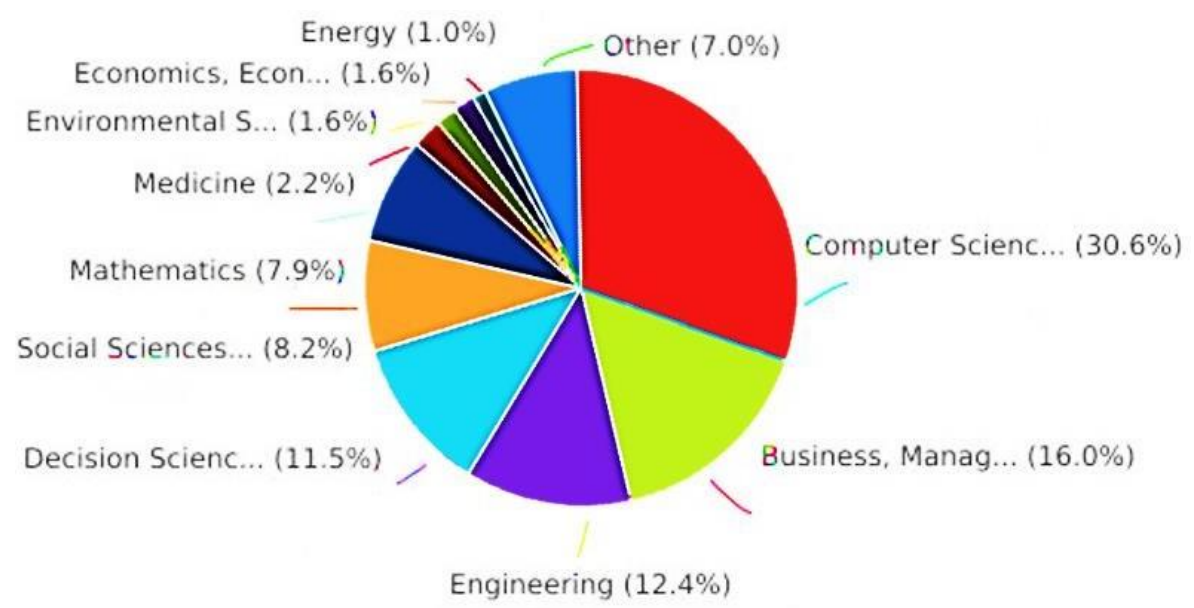

Figure 1: Knowledge management documents published by subject area during the past two decades from 2000 to 2020. Source: (scopus,2021) 


\subsection{Knowledge management processes:}

The principal goal of the knowledge management processes (KMPs) is to enhance the organization's productivity and to efficiently use the organization's collective knowledge. They refer to all the activities that relate to knowledge inside and outside the organization (Alharithy, 2015). They facilitate the transformation of tacit knowledge into explicit and explicit

${ }^{1}$ Scopus database is one of the major search engines and is commonly used among researchers (Yi \& Yang, 2014), which includes comprehensive coverage of scientific outputs. In 2020, the database has more than 40 thousand scientific journals (Scopus, 2021a).

knowledge into tacit (Titi, 2010). Different scholars have defined KMPs in diverse dimensions, as shown in Table 1.

\section{Table 1: Models of different KMPs}

No Authors Knowledge Management processes

$1 \quad$ (De Long, 1997)

2 (Teece, 1998)

3 (Burk, 1999)

$4 \quad$ (Alavi \& Leidner, 2001)

5 (Tserng \& Lin, 2004)

6 (Alegbeleye, 2010)

7 (Abdelatif et al., 2013)
Capture-Transfer-Use.

Create-Transfer-Assemble-Integrate-Exploit.

Find/Creation-Organization-Sharing- Use/Reuse.

Creation-Storage-Transfer-Application.

Creating-Securing-Capturing/Combining-Distributing-

Retrieving.

Acquisition and Generation-Capture-Organization- Storage-

Sharing-Application.

Creation-Storage-Sharing-Application-Evaluation. 
Based on the previous table, there are many models of KMPs that define the relationship between the basic processes that extend from three processes (creation, organization, and transferring) to seven processes (creation, acquisition, identification, adaptation, organization, distribution, application) (King, 2009). KMPs include four main stages in most organizations (Jashapara, 2004) as below;

Knowledge creation is the continuous transfer, combination, and reconfiguration of different types of knowledge, as it occurs through interaction, practice, and action (Nonaka \& Takeuchi, 1995). knowledge creation is the driving force of the organization and indicates its ability to generate new or unique ideas (Ichijo \& Nonaka, 2006).

Knowledge Storage refers to a process of transformation that includes organizing, storing, structuring, and combine knowledge so that concerned easily used it in the future (Lin, 2007).

Knowledge sharing is "the processes of exchange of the knowledge between individuals in the organization, it's a two-way interaction" (Françoise, 2008).

Knowledge application is a process that facilitates organizations to convert their organizational expertise into a tangible product by using actual knowledge (Zaied et al., 2012). It supports organizations to increase their performance and decrease costs (Davenport \& Klahr, 1998).

\subsection{Knowledge management enablers factors:}

Knowledge management enabler indicates the key factors that define the effectiveness of KM within the institution, that are the driving power that supports KM (Yeh et al., 2006). KMincludes processes to manage knowledge as well as enablers to support these processes. Manyresearchers have presented KM enablers for KM application in the literature, as shown in Table 
INTERNATIONAL JOURNAL OF

\section{Table 2: KM enabler's factors}

\begin{tabular}{|c|c|c|}
\hline No & Authors & KM enablers factors \\
\hline 1 & (Choi \& Lee, 2003) & leadership, Organization, technology, and learning \\
\hline 2 & Davenport, & $\begin{array}{l}\text { Leadership, organizational policy, performance } \\
\text { measurement, }\end{array}$ \\
\hline & & $\begin{array}{l}\text { knowledge sharing and acquisition, benchmarking and training, } \\
\text { information systems structure. }\end{array}$ \\
\hline 3 & (Wong \& Aspinwall, 2005) & $\begin{array}{l}\text { information technology and organizational infrastructure, strategy } \\
\text { culture, and purpose, measurement and management leadership } \\
\text { support }\end{array}$ \\
\hline 4 & (Akhavan et al., 2006) & $\begin{array}{l}\text { culture, leadership, structure, roles and IT } \\
\text { infrastructures, } \\
\text { responsibilities, and measurement }\end{array}$ \\
\hline 5 & (Consulting, 1999) & corporate culture, people and information technology \\
\hline
\end{tabular}

The extended list of KM enablers' factors can be classified into four main categories; people, organization culture, organization structure, and technology, which are essential for KM effectiveness.

People play a vital role in KM success and organization since they are the creative source. Knowledge is possessed by individuals and the sharing, using, and converting personal knowledge to organizational knowledge by enhancing an individual's communication with others is an important step (Nonaka \& Takeuchi, 1995). So, several successful organizations

get ready to invest in their employees to support their experiences, capabilities, and visions for the global working environment (Bozbura, 2007).

Organizational culture: it is considered a complicated collection of beliefs, values, and behaviors that affects KM in organizations (Ho, 2009). Each organization possesses its own unique practices and culture (Shin et al., 2001). 
Technology: Convenient technology infrastructure is necessary for efficient KM. It comprises information technology (IT) systems that facilitate the integration of knowledge and information in the organization(Webb \& Schlemmer, 2006). KM can be supported by applications of IT tools to create an infrastructure for enhancing the scope and efficiency of the KM processes like creation; storage, transfer, and application (Easterby-Smith \& Lyles, 2003).

Organizational structure refers to the method and scope to which roles and responsibilities are delegated, coordinated, and controlled, and how information streams among various management levels to achieve the objectives and goals of the organizations. Organization structure includes rules, regulations, the organizational hierarchy, and reporting relationships (Herath, 2007).

\subsection{Knowledge management and the construction sector:}

Knowledge is beheld to be a significant asset for organizations. Knowledge management KM in the construction sector, which is characterized by intensive knowledge(Kim, 2014). The expression "knowledge-intensive" intimates economists' labeling of companies as labor- intensive or capitalintensive. By analogy, labeling a company as knowledge-intensive presumes that knowledge has more significance than other inputs. The industry has begun to realize that knowledge is an asset, quite such as the physical assets of companies(Zhang, 2010).

Effective KM in construction companies enhances the interaction of the skills and experiences of stakeholders during the project life cycle, contributes to preventing the recurrence of past mistakes and "reinvention of the wheel"(Tan et al., 2006). KM plays a vital role in innovation, building client satisfaction(Lee \& Egbu, 2007), entrepreneurship, and improving organizational competitiveness(Tan et al., 2006). The positive effects of a successful KM system implicate project reduced time consumption, costs, and increased quality (Park et al., 2013).

By following the path of documents published in Scopus database by year that relate to the subject of KM in construction industry in the period between 2000-2020(Scopus, 2021b) as shown in Figure 2, it was revealed that many researchers have gradually become interested in the research in this field. 


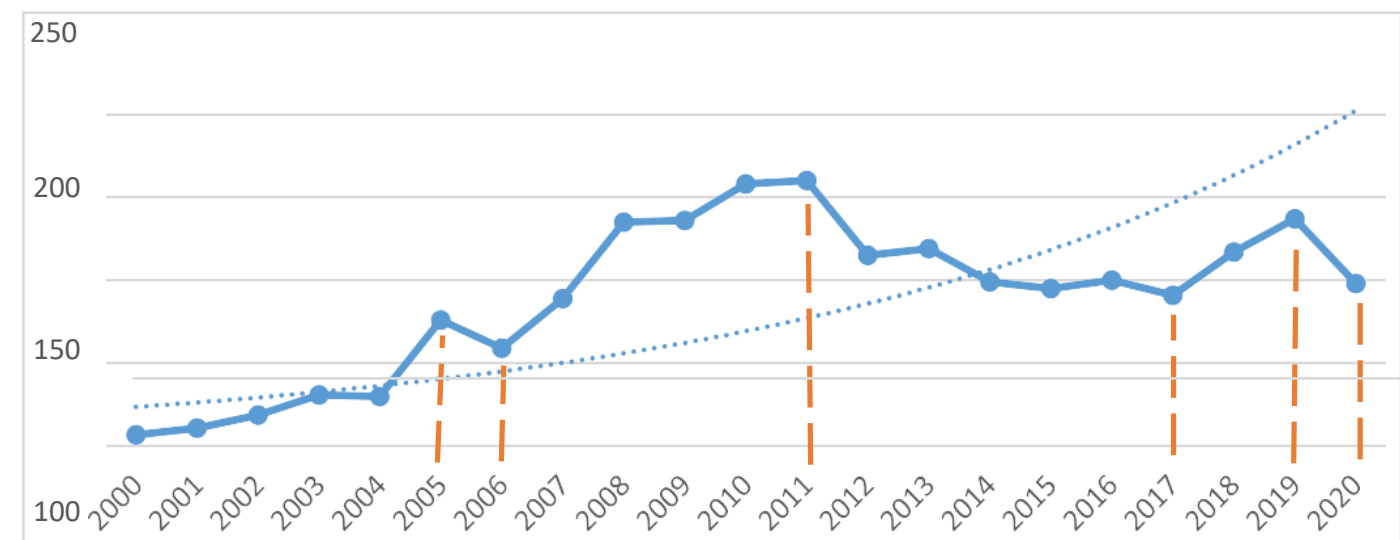

Figure 2: the path of documents puplished in scopus datadase by year in the field of knowledge management in construction last two decad source: (scopus,2021b)

The data of the previous figure were got by using various keywords associate with the topic; Title-abstract-key ( ("knowledge management," or limit to exact keyword, "knowledge management system," or "knowledge creations" or "knowledge transfer" or "knowledge acquisition" or "knowledge-sharing" or "knowledge exchange") and ("construction" or limit to exact keyword, "construction industry" or "construction firms" or "construction companies" or "construction projects" or "construction sectors" or "construction organizations" or "construction enterprise") and (limit to (subject area," engineering") or "business and management")).

The literature review yielded 1883 documents that were published in the period from 2000 to 2020. We divided this period into six phases, which varied between ups and downs. The first phase from 2000 to 2005 represented the early stages of its ascent, in which the curve continued to rise, and the number of documents published annually increased from 7 to 76 documents. While the period between 2005 and 2006 showed a decrease in the number of published documents, to 59 documents. As for the period from 2006 to 2011, the curve rose again until it reached its peak in 2011 when the number of documents published reached 160 documents. On the contrary, we considered the period between 2012 and 2017 a period of fluctuation, as the numbers decreased in 2012 to reach 112 documents and continued to oscillate between ups and downs until the published documents reached 91 in 2017.

The curve rose again from 2017 to 2019, bringing the number of documents published in the year 2019 to 137 documents. As for the year 2020, because of the emergence of the Corona epidemic, which affected scientific research at the global level, the number of published documents decreased to 90 documents. In general, the trend line for the number of documents published annually during the past two decades in knowledge management in the construction industry continues to rise significantly. 
There has been quite inclusive research showed on the application, the role, and practices of KM in the construction sector. Forcada et al. (2013) presented a survey of awareness of KM application in the Spanish construction sector(Forcada et al., 2013), Patricia Carrillo \& Chinowsky (2006) discussed the implementation of KM initiatives in leading engineering design and construction organizations in the USA(Carrillo \& Chinowsky, 2006), ElFar et al. (2017) studied The effect of applying KM on performing Egyptian construction companies(ElFar et al., 2017), Oke et al. (2013) assessed the adoption of KM practices among Nigerian construction professionals(Oke et al., 2013), Yusof \& Bakar (2012) reported KM and growth performance in construction companies(Yusof \& Bakar, 2012).

\section{2-6 Knowledge management and building information modeling}

Outspread building information modeling (BIM) technology into the construction process to make a single repository of data(Goedert \& Meadati, 2008). BIM supply a coordinated source of organized information to shore all parties implicated in the delivery process such as design, build, or operation. BIM merge technology together with new activities practices to progress the quality of the delivered output as well as improve the accuracy, timeliness, and coherence of the process(Charlesraj, 2014).

However, the present BIM approach is not ripped enough to create and capture knowledge, and knowledge management is an independent and freelance process detached from BIM application. As both KM and BIM are executed all through the life cycle of a project, it is feasible and appropriate to smash their border and merge them into Building Knowledge modeling BKM (Liu et al., 2013). KMS (that stores knowledge in a KM repository) and BIM applications are linked and operated together to satisfy information exchange demands of BIM utilizes and knowledge capture, sharing, reuse, and maintenance demands of KM. This is the essence of the suggested BKM approach, as shown in Figure 3.

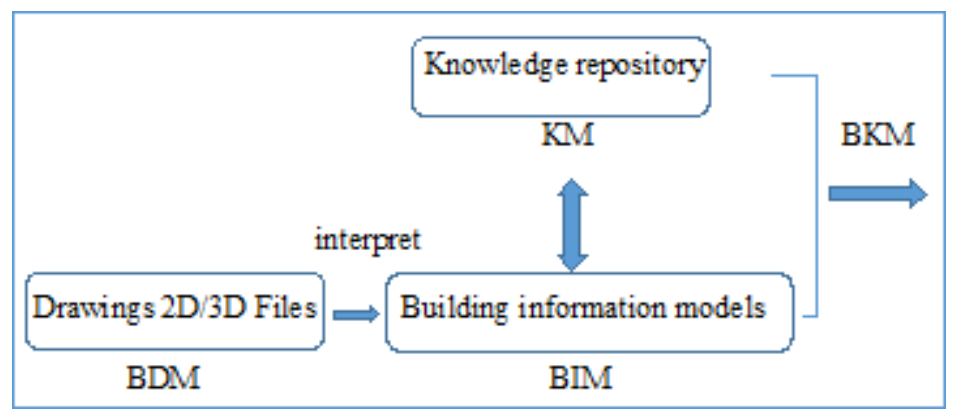

Figure 3: Development of KM, BDM, and BIM to BKM Source: (Liu et al., 2013) 


\subsection{Small enterprises in Egyptian construction industry:}

Definition of small enterprises: Micro, small and medium enterprises MSMEs are the spine of any economy, they play a vital role in the development and economic growth. The criteria for defining SMEs differ among countries or sometimes among industries. Egbu et al. (2003) Clarified there is no particular and uniformly agreeable definition of a small enterprise, However, the World Bank distinguished between MSMEs according to several criteria: the number of employees, size of the organization's assets, and annual turnover. Small enterprises SEs are defined as enterprises have with 10 to 50 employees, and the size of the enterprise's assets and annual sales do not exceed 3 million USD(Dababneh \& Tukan, 2007). According to Egyptian law, no. (141/2004) distinguished SMEs focused on two criteria: the number of employees and the enterprise's capital. SEs have less than 50 employees and capital between 50 thousand EGP and 1 million EGP(Accelerate Consulting and Deveploment, 2014).

Small enterprises in Egypt: SMEs in Egypt are estimated at 95\% to 98\% of the total industrial establishments(Bary, 2019). MSMEs are Distributed over 3.653 million enterprises, representing $75 \%$ of the total workforce in Egypt. The number of SEs reached 216.9 thousand out of the total number of MSMEs(CAPMAS, 2020), as shown in Figure.

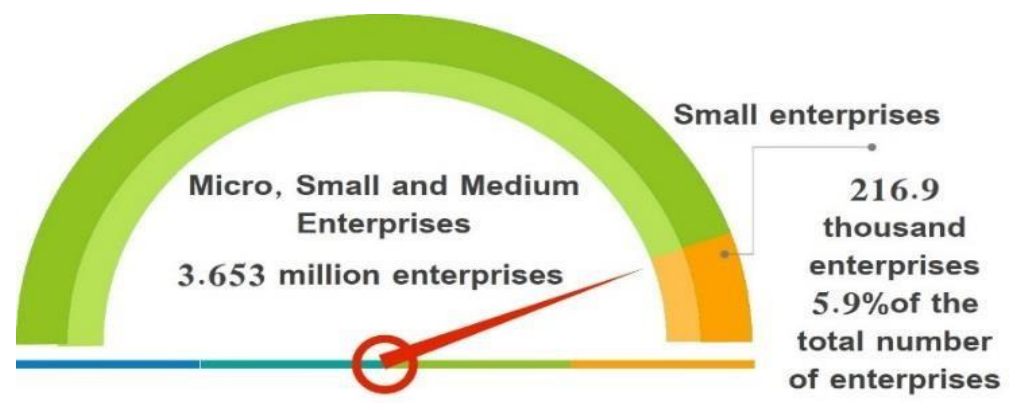

Figure 4: The number of small enterprises out of the total number of MSMEs In Egypt in 2017-2018.

\section{Source: constructed by author using (CAPMAS, 2020)}

Small enterprises in Egyptian construction industry: The form of the construction industry like a hierarchical pyramid, wherever the top part comprises large companies and the base comprises relatively SEs. SMEs include a majority of all enterprises and employ a greater number of workers(Balaban-Ökten \& Gundes, 2018). the number of SEs are estimated to be around $80 \%$ of the enterprises officially registered with the Egyptian Federation of Construction and Building Contractors (EFCBC) in July 2019(Hamdan, 2019), as shown in Figure 5. 


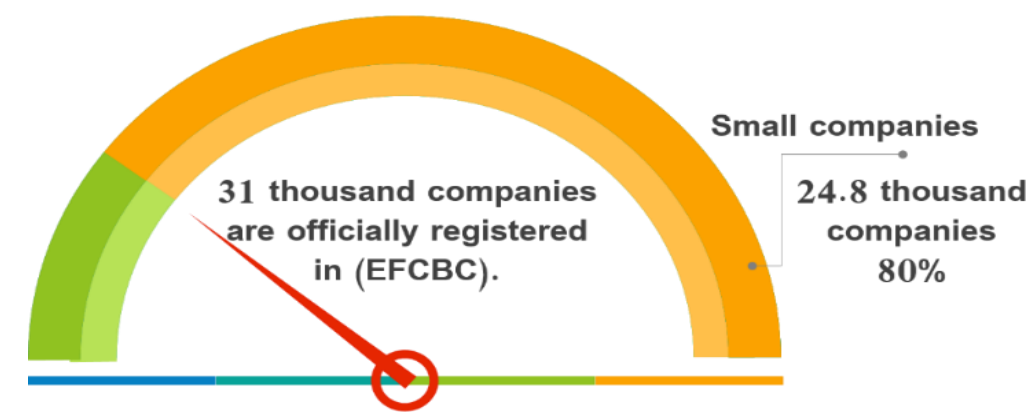

Figure 4: Small enterprises registered in (EFCBC) in July 2019. Source: constructed by author using (Hamdan,2019)

\subsection{Obstacles to applying knowledge management in construction sector and small enterprises:}

Although many studies have shown an increased awareness of the concept of KM in the construction sector, several barriers are hindered in the application of KM practices (BalabanÖkten \& Gundes, 2018). These barriers arise because of the nature of construction projects in general and the characteristics of SEs in particular. Despite the unique nature of construction projects, there are many experiences that can be used in future projects(Kulkarni \& Dahiya, 2018). Because of the temporary project-based nature with significant disassembles, and increased worker turnover (Okere, 2017), the organizations dissolve at the end of the project, and the knowledge generated from this project is lost. Loss of knowledge gained through the project leads to further difficulties and problems in achieving accomplishment for projects in the future, as well as losing organizational knowledge(Kulkarni \& Dahiya, 2018). On the other hand, several researchers focused on the different risks and threats of incorporating $\mathrm{KM}$ in the construction sector, as shown in Table 3.

Table 3: obstacles to applying KM in the construction sector

No Authors Focus group / Obstacles to applying KM

Civil engineering construction firms in Ghana/

1 (Hackman Unavailability of KMS, lack of support from top management, shortage et al.,of awareness of KM practices, lack of realization of KM, employee 2017) resistance. 


\section{No Authors Focus group / Obstacles to applying KM}

\section{Civil engineering construction firms in Ghana/}

1 (Hackman Unavailability of KMS, lack of support from top management, shortage et al,of awareness of KM practices, lack of realization of KM, employee resistance.

\section{No Authors $\quad$ Focus group / Obstacles to applying KM}

\section{Civil engineering construction firms in Ghana/}

1 (Hackman Unavailability of KMS, lack of support from top management, shortage et al.,of awareness of $\mathrm{KM}$ practices, lack of realization of $\mathrm{KM}$, employee 2017) resistance.

\section{construction companies in UAE/}

2 (Ghabbour, The nature of construction projects, the minimal reviews and 2017) documentation after the completion of project implementation, limited time, lack of support from senior

management, and organizational culture do not support new ideas and technologies.

The Saudi Construction Industry/

3 (Al Olyani, Individual barriers; lack of time, experience level, difference of 2007) background and culture.

Organizations barriers; lack of motivation, lack of resources.

Technology barriers; lack of technical support, lack of communication.

Construction sector in north America/

4 (Okere, 2017) lack of awareness of knowledge as the most important resource, Lack of an appropriate culture and environment to promote knowledge transfer 
practices, and

lack of efficient ICT systems.

Civil Engineering Construction Firms in Nigeria/

5 (Alhaji et al.,Lack of documentation of experiences and knowledge, Lack of 2013) knowledge sharing among employee, Lack of understanding of the concept knowledge, Moving from one organization to another without documenting knowledge, No person responsible for

documenting records.

UK Construction sector/

6 (Carrillo et al., Employee Resistance, Lack of Standard Work Processes, Not Enough 2004) money, lack of

Time, Lack of IT Infrastructure, Organizational Culture.

large construction organizations/

7 (Robinson etResistance of employee, time constraint, organizational culture, al., 2001) insufficient money, lack of standard work processes, poor IT infrastructure, lack of understanding of KM.

SMEs in the Turkish AEC industry/

8 (Balaban- SEs didn't use a systematic KM system and the principles barriers were; Ökten \& not storing knowledge in an organized and systematic way, most Gundes, 2018) institutions prefer to keep hard copies of documents and share them via e-mail, Difficulties converting tacit knowledge into explicit knowledge, and Computer hardware malfunctions caused a

loss of knowledge.

Korean Small and Medium-sized Construction Companies/ 
construction companies in UAE/

2 (Ghabbour, The nature of construction projects, the minimal reviews and 2017) documentation after the completion of project implementation, limited time, lack of support from senior

management, and organizational culture do not support new ideas and technologies.

The Saudi Construction Industry/

3 (Al Olyani, Individual barriers; lack of time, experience level, difference of 2007) background and culture.

Organizations barriers; lack of motivation, lack of resources.

Technology barriers; lack of technical support, lack of communication.

Construction sector in north America/

4 (Okere, 2017) lack of awareness of knowledge as the most important resource, Lack of an appropriate culture and environment to promote knowledge transfer practices, and

lack of efficient ICT systems.

Civil Engineering Construction Firms in Nigeria/

5 (Alhaji et al.,Lack of documentation of experiences and knowledge, Lack of 2013) knowledge sharing among employee, Lack of understanding of the concept knowledge, Moving from one organization to another without documenting knowledge, No person responsible for

documenting records.

UK Construction sector/

6 (Carrillo et al., Employee Resistance, Lack of Standard Work Processes, Not Enough 2004) money, lack of

Time, Lack of IT Infrastructure, Organizational Culture. large construction organizations/ 
7 (Robinson etResistance of employee, time constraint, organizational culture, al., 2001) insufficient money, lack of standard work processes, poor IT infrastructure, lack of understanding of KM.

SMEs in the Turkish AEC industry/

8 (Balaban- $\quad$ SEs didn't use a systematic KM system and the principles barriers were; Ökten \& not storing knowledge in an organized and systematic way, most Gundes, 2018) institutions prefer to keep hard copies of documents and share them via e-mail, Difficulties converting tacit knowledge into explicit knowledge, and Computer hardware malfunctions caused a

loss of knowledge.

Korean Small and Medium-sized Construction Companies/

9 (Park et al.,Insufficient funding, Problems of imparting the knowledge at the right 2013) time to the right person, not sharing KM, The challenge of integrating and implementing knowledge.

SMEs in Malaysian construction industry/

10 (Yap \& Lock,Lack of motivation, distrust, Difficulty accessing knowledge when it is 2017) needed, loss of an important knowledge, bureaucracy.

\section{construction SMCs in South Africa/}

11 (Aghimien etpeople- related barriers: Lack of innovation and research, al., 2019) management's/Owner's unwillingness to share knowledge, Lack of training programs, and Lack of aspiration of staff.

Organizational barriers; difficulty of funds, high-priced IT system, lack of planning, lack of resources, and inability to hire experts.

Project demand barriers; Time restrictions to share knowledge, lack of recognition and

rewards, and lack of information analysis.

SMEs in Indian Construction Industry/

12 (Kulkarni Lack of technology system, lack of motivation, reliability of knowledge $\& \quad$ resources, heavy workload, Lack of high management support, Fear of 
Dahiya, 2018) losing and controlling of

knowledge possessions.

\section{FINDING OF THE LITERATURE REVIEW:}

Through the wide-ranging searches showed above, previous studies revealed that most small construction enterprises SCEs possess no explicit strategy and knowledge management program. They prefer adopting informal knowledge since the establishment of formal knowledge will be more costly compared to informal. We can divide the key obstacles associated with the application of the KM system in SCEs into three obstacles; individual, organizational, and technological obstacles, and there were several issues that were categorized as barriers to implementing KM in SCEs, as shown in Table4.

Table 4: Obstacles to applying knowledge managementin small construction enterprises

\begin{tabular}{lll}
\hline No & Types of Obstacles & Obstacles to knowledge management application \\
\hline $1 \quad$ Individual obstacles & 1- & Culture differences \\
& 2- & Limited time for knowledge sharing 3- Employee \\
& resistance \\
\hline \multirow{4}{*}{ Organizational obstacles } & 4- A lack of motivation \\
& 5- A different level of experience \\
& 1- Organizational culture \\
& 2- Budgetary constraints \\
& 3- A lack of documentation of experience and knowledge \\
& 4- Limited resources \\
& 5- A lack of top management support \\
& 1- A lack of a robust technical infrastructure \\
& 2- Shortage of technical support \\
& 3- A lack of training.
\end{tabular}

Source: constructed by author using (Aghimien et al., 2019; Balaban-Ökten \& Gundes, 2018; Kulkarni \& Dahiya, 2018; Park et al., 2013; Yap \& Lock, 2017).

We can consider these results as a starting point for small construction enterprises. It can help set standards for effective knowledge management adoption. They must create a balanced and integrated structure between individual, organizations, and technology to implement more successful knowledge management systems. 


\section{CONCLUSION:}

From the foregoing discussion, the application of KM strategies is a significant issue. There is a need to adopt effective KM to enable SCEs to gain, store, share, apply, and reuse project-related knowledge efficiently during the project life cycle and after its completion. Culture, structure, leadership, finance, people, and technology can identify the main parameters affecting KM adoption in SEs. In this context, SEs must adopt a knowledge management strategy to enhance and develop their performance, as well as to achieve a competitive advantage. So, it is essential to be aware of the difficulties and barriers that may constrain the successful application of KM initiatives. The three major obstacles to applying KMS in SCEs were individual, organizational, and technological obstacles.

Hence, SCEs need to have a convenient plan and develop an appropriate strategy to overcome any difficulties or problems for the KM system to be applied efficiently. It is essential to build and enhance a culture that rewards employees for creating and sharing knowledge. The organizations should create sufficient time for exchanging experience, support the creation of new knowledge and innovation to enhance the opportunity of learning culture. There is an urgent necessity for using programs and technology to facilitate the communication and transfer of knowledge between stakeholders.

Ultimately, the result of this paper could broadly describe the barriers associated with applying $\mathrm{KM}$ in SCEs in order to differentiate best practices, avoid causes that could obstruct effective $\mathrm{KM}$, and present recommendations compatible with the needs of SCEs.

\section{References:}

Abdelatif, L., Kerzabi, A., \& Mustapha, H. (2013). The formalization of the knowledge management in the managerial approach in the Algerian firms: case of the territorial direction of Algeria telecom of Tlemcen. Mediterranean Journal of Social Sciences, 4(6).

Accelerate Consulting and Deveploment. (2014). micro, small and medium Enterprises in Egypt (Issue August).

Aghimien, D., Aigbavboa, C. O., Gomes, F., \& Thwala, W. D. (2019). Barriers to Knowledge Management in Small and Medium Construction Companies in South Africa. Proceedings of the Creative Construction Conference, 213-219.

Akhavan, P., Jafari, M., \& Fathian, M. (2006). Critical success factors of knowledge management systems: a multi-case analysis. European Business Review, 18(2), 97-113. 
Al Olyani, S. M. (2007). Barriers to Knowledge Management Implementation in the Saudi Construction Industry. Heriot-Watt University.

Alavi, M., \& Leidner, D. E. (2001). Review: Knowledge management and knowledge management systems: Conceptual foundations and research issues. MIS Quarterly: Management Information Systems, 25(1), 107-136.

Alegbeleye, B. (2010). Old wine in new bottle: A critical analysis of the relationship between knowledge and library and information science. Paper Presented at the 48th National Conference of the Nigeria Library Association.

Alhaji, K. M., Amiruddin, R., \& Abdullah, F. (2013). Project Knowledge Management in Civil Engineering Construction Firms In Nigeria. Australian Journal of Basic and Applied Sciences, $7(2), 54-62$.

Alharithy, M. (2015). Knowledge Management Process in several organizations: Analytical

Study of modeling and several processes. International Conference on Communication, Management and Information Technology, 65, 726-733.

Aouad, G., \& Arayici, Y. (2010). Requirements Engineering for Computer Integrated Environments in Construction. Wiley-Blackwell, Oxford.

Bakar, A. H. A., Virgiyanti, W., \& Tufail, M. A. (2012). Knowledge management processes and competitive advantage in construction industry. Emerging Issues in the Natural and Applied Sciences, 2(1), 81-102.

Balaban-Ökten, B., \& Gundes, S. (2018). Knowledge Management in Small and Medium Architecture, Engineering and Construction Firms in Turkey. Electronic Journal of Knowledge Management, 16(2), 155.

Bary, A. (2019). SMEs Sector: A Key Driver to the Egyptian Economic Development. SSRN Electronic Journal, 93034. https://doi.org/10.2139/ssrn.3334845

Boyes, B. (2016). Moving from information to knowledge management in the construction industry. RealKM. real.km.com/2016/10/12

Bozbura, F. T. (2007). Knowledge management practices in Turkish SMEs. Journal of Enterprise Information Management, 20(2), 209-221.

Burk, M. (1999). Knowledge Management: Everyone Benefits by sharing information. In Research Technology Management. Public Roads,Nov-Dec. 
CAPMAS. (2020). Arab Republic of Egypt - Egyptian Economic Census 2017/2018, Economic Census Egypt 2017 /2018. CAPMAS. https://censusinfo.capmas.gov.eg/Metadata-arv4.2/index.php/catalog/1592

Carrillo, P., \& Chinowsky, P. (2006). Exploiting Knowledge Management: The Engineering and Construction Perspective. Journal of Management in Engineering, 22(1), 2-10. https://doi.org/10.1061/(asce)0742-597x(2006)22:1(2)

Carrillo, P., Robinson, H., Al-Ghassani, A., \& Anumba, Chimay, J. (2004). Knowledge Management in UK Construction strategies,resources and barriers. Project Management Journal, 35(April 2013), 1-71.

Charlesraj, V. P. C. (2014). Knowledge-based building information modeling (K-BIM) for facilities management. 31st International Symposium on Automation and Robotics in Construction and Mining, ISARC 2014 - Proceedings, Isarc, 936-941.

Choi, B., \& Lee, H. (2003). Knowledge management enablers, processes, and organizational performance: An integrative view and empirical examination. Journal of Management Information Systems, 20(1), 179-228.

Consulting, A. A. B. (1999). Zukai Knowledge Management. Tokyo: Toyo Keizai.

Dababneh, R., \& Tukan, F. (2007). Booklet of Standardized Small and Medium Enterprises Definition. In USAID.

Davenport, T. H., \& Klahr, P. (1998). Managing customer support knowledge. California Management Review, 3, 195-208. https://doi.org/10.2307/41165950

De Long, D. (1997). Building the knowledge-based organization: How culture drives knowledge behaviors. In Centers for Business Innovation-Working Paper.

Durst, S., Runar Edvardsson, I., \& Bruns, G. (2013). Knowledge creation in small construction firms. Journal of Innovation Management Durst, 1, 125-142.

Earl, M. (2001). Knowledge management strategies: toward a taxonomy. Journal of Management Information Systems, 18(1).

Easterby-Smith, M., \& Lyles, M. A. (2003). The Blackwell Handbook of Organizational Learning and Knowledge Management.

Egbu, C., Hari, S., \& Kumar, B. (2003). Knowledge Management Practices in Small and Medium Enterprises in the Construction Industry. Association of Researchers in Construction Management, 2(January), 3-5. 


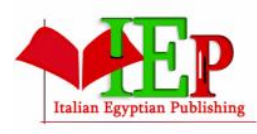

ISSN: $2785-9673$
INTERNATIONAL JOURNAL OF

ARCHITECTURAL ENGINEERING AND URBAN

RESEARCH

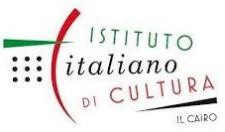

www.egyptfuture.org/ojs/

ElFar, A., Elsaid, A. M., \& Elsaid, E. (2017). How knowledge management implementation affects the performance of Egyptian construction companies. Journal of Applied Business Research, 33(3), 409-438.

Forcada, N., Fuertes, A., Gangolells, M., Casals, M., \& Macarulla, M. (2013). Knowledge management perceptions in construction and design companies. Automation in Construction, 29, 83-91.

Françoise, R. (2008). Transfert des connaissances: stratégies, moyens d'action, solutions adaptées à votre organisation. Lavoisier, Paris, 278.

Ghabbour, M. (2017). Knowledge Management Practices in UAE Construction Sector (Issue November). The Biritish university in Duabi.

Goedert, J. D., \& Meadati, P. (2008). Integrating Construction Process Documentation into Building Information Modeling. Journal of Construction Engineering and Management, 134(7), 509-516.

Hackman, J., Agyekum, K., \& Smith, B. (2017). Challenges To the Adoption of Knowledge Management in Civil Engineering Construction Firms in Ghana. February. 
Macintosh, A. (1997). position paper on knowledge asset management. Artifitial Intelligence Applications Institute, University of Adinburgh.

Muriithi, S. (2017). African small and medium enterprises (SMEs) contributions, challenges and solutions.

Nonaka, I., \& Takeuchi, H. (1995). the knowledge creating company ,how Japanese companies create dynamics of innovation. Oxford University Press.

O’Dell, C., \& Leavitt, P. (2004). The Executives Role in Knowledge Management, American Productivity \& Quality Center (APQC), Houston.

Oke, A. E., Ogunsemi, D. R., \& Adeeko, O. C. (2013). Assessment of knowledge management among construction professionals in Nigeria. Journal of Construction Project Management and Innovation, 3(2), 660-679.

Okere, G. O. (2017). Barriers and Enablers of Effective Knowledge Management: A Case in the Construction Sector. The Electronic Journal of Knowledge Management, 15(2), 85-97.

Park, M., Jang, Y., Lee, H. S., Ahn, C., \& Yoon, Y. S. (2013). Application of knowledge management technologies in Korean small and medium-sized construction companies. KSCE Journal of Civil Engineering, 17(1), 22-32.

Probst, G., \& Davenport, T. . (2002). Knowledge Management Case Book. Best Practices, 2nd ed.

Robinson, H. S., Carrillo, P. M., Anumba, C. J., \& Al-Ghassani, A. M. (2001). Perceptions and barriers in implementing knowledge management strategies in large construction organisations. RICS Foundation Construction and Building Research Conf. (COBRA), January 2014, 451-460.

Rowley, J. (2007). The wisdom hierarchy: representations of the DIKW hierarchy. Journal of Information Science, 33(2), 163-180. https://doi.org/10.1177/0165551506070706

Rumizen, M. C. (2002). The complete idiot's guide to knowledge management ALPHA, Madison.

Scopus. (2021a). About Scopus - Abstract and citation database | Elsevier. https://08101mso1- 1105-y-https-www-elsevier-com.mplbci.ekb.eg/solutions/scopus

Scopus. (2021b). Scopus - Analyze search results. https://08105e3nd-1103-y-httpswwwscopus- 
com.mplbci.ekb.eg/term/analyzer.uri?sid=4b470bd5da3f616cda7a000141d7fc24\&ori gin

$=$ resultslist $\& \mathrm{src}=\mathrm{s} \& \mathrm{~s}=\mathrm{TITLE}-\mathrm{ABS}-$

$\mathrm{KEY}+\% 28 \% 22 \mathrm{knowledge}+$ management\%22+AND+construction\%29\&sort=plf$\mathrm{f} \& \mathrm{sdt}=\mathrm{cl} \&$ sot $=\mathrm{b} \& \mathrm{sl}=55 \&$ count $=1899 \&$ analyzeR

Scopus. (2021c). sso @ 08105mpct-1105-y-https-www-scopus-com.mplbci.ekb.eg.

Shin, M., Holden, T., Schmidt, R. A., \& Schmidt, R. A. (2001). From knowledge theory to management practice: towards an integrated approach. Information Processing and Management, 37, 335-355. www.elsevier.com/locate/infoproman

Tan, H. C., Carrillo, P., Anumba, C., Kamara, J. M., Bouchlaghem, D., \& Udeaja, C. (2006). Live capture and reuse of project knowledge in construction organizations. Knowledge Management Research \& Practice, 2006(4), 149-159.

Teece, D. J. (1998). Capturing Value from Knowledge Assets: The New Economy, Markets for Know-How, and Intangible Assets. California Management Review, 40(3), 55-79. https://doi.org/10.2307/41165943

Titi, K. M. I. (2010). Knowledge Management Challenges, Technologies and Solutions. Al- Hamed for Publishing and Distribution.

Tserng, H. P., \& Lin, Y. C. (2004). Developing an activity-based knowledge management system for contractors. Automation in Construction, 13(6), 781-802.

van Donk, D. P., \& Riezebos, J. (2005). Exploring the knowledge inventory in project-based organisations: A case study. International Journal of Project Management, 23(1), 75-83. Walsh, J. . (1995). Managerial and organizational cognition: Notes from a trip down memory

lane. Organization Science, 6(3), 280-321.

Webb, B. ., \& Schlemmer, F. (2006). The impact of strategic assets on financial performance and on internet performance. Electronic Markets, 16(4), 371-385.

Wong, K., \& Aspinwall, E. (2005). An empirical study of the important factors for knowledgemanagement adoption in the SME sector. Journal of Knowledge Management, 9(3), 64-82.

Yap, J. B. H., \& Lock, A. (2017). Analysing the benefits, techniques, tools and challenges of knowledge management practices in the Malaysian construction SMEs. Journal of Engineering, Design and Technology, 15(6), 803-825. 
Yeh, Y. J., Lai, S. Q., \& Ho, C. T. (2006). Knowledge management enablers. Industrial Management \& Data Systems, 106(6), 793-810.

Yi, H., \& Yang, J. (2014). Research trends of post disaster reconstruction: the past and the future. HabitatInternational, 42, 21-29.

Yusof, M. N., \& Bakar, A. H. A. (2012). Knowledge Management and Growth Performance in Construction Companies: A Framework. Procedia - Social and Behavioral Sciences, 62, 128-134. https://doi.org/10.1016/j.sbspro.2012.09.022

Zaied, A., Hussein, G., \& Hassan, M. (2012). The Role of Knowledge Management in Enhancing Organizational Performance. International Journal of Information Engineering and Electronic Business, 4(5), 27-35.

Zhang, T. (2010). Application of Knowledge Management in Public Administration. International Conference on Educational and Network Technology. www.krii.com/downloads/km

EL-FEKI, Adel, Ismail, Hamid MANSI, Wala, Nasser, AN APPLIED PROJECT TOWARDS SUSTAINABLE PRODUCTIVITY DEVELOPMENT IN KAFR MAKAWI -

ZAGAZIG CITY - SHARKIA GOVERNORATE, International Journal of Architectural Engineering and Urban Research, Vol.3, No.2, 2020, pp. 6-14.

Hari, S., Egbu, C., \& Kumar, B. (2004). Knowledge Capture in Small and Medium Enterprises in the Construction Industry: Challenges and Opportunities. 20th Annual ARCOM Conference, 2(September), 847-858.

Herath, S. . (2007). A framework for management control research. Journal of Management Development, 26(9), 895-915.

Ho, C. (2009). The relationship between knowledge management enablers and performance.

Industrial Management \& Data Systems, 109(1), 98-117.

Huang, L.-Y., \& Yeh, Y.-C. (2011). Knowledge management in blended learning: Effects on professional development in creativity instruction. Computers \& Education, 56(1). https://doi.org/10.1016/j.compedu.2010.08.011

Ichijo, K., \& Nonaka, I. (2006). Knowledge creation and management: New challenges for managers. 
Jashapara, A. (2004). knowledge Management: An integrated approach. FT Prentice Hall.

Kim, S. B. (2014). Quantitative evaluation on organizational knowledge implementation in the construction industry. KSCE Journal of Civil Engineering, 18(1), 37-46.

King, W. R. (2009). Knowledge Management and Organizational Learning (pp. 313). https://doi.org/10.1007/978-1-4419-0011-1_1

Kulkarni, R., \& Dahiya, R. (2018). Implementation Barriers for Knowledge Management for SMEs in Indian Construction Industry (pp. 1-68).

Lee, C. C., \& Egbu, C. O. (2007). ITcon paper: Information technology tools for capturing and communicating learning and experiences in construction SMEs in developed and developing countires. Electronic Journal of Information Technology in Construction, 167-180.

Lin, H. F. (2007). A stage model of knowledge management: an empirical investigation of process and effectiveness. Journal of Information Science, 33(6), $643-659$.

Liu, F., Jallow, A. K., Anumba, C. J., \& Wu, D. (2013). Building Knowledge Modeling : Integrating Knowledge in Bim. Cib W78, 30, 9-12.

Received: April 2021

Accepted: June 2021 